\title{
Inhibition of TGF-B1 suppresses motility and invasiveness of oral squamous cell carcinoma cell lines via modulation of integrins and down-regulation of matrix-metalloproteinases
}

\author{
SAYAKA TAKAYAMA, MASASHI HATORI, YUJI KURIHARA, YURIKO KINUGASA, \\ TATSUO SHIROTA and SATORU SHINTANI

\begin{abstract}
Department of Oral and Maxillofacial Surgery, School of Dentistry, Showa University, 2-1-1, Kitasenzoku, Ota-ku, Tokyo 145-8515, Japan
\end{abstract}

Received August 6, 2008; Accepted October 2, 2008

DOI: 10.3892/or_00000209

\begin{abstract}
Transforming growth factor (TGF)- $\$ 1$ is a multifunctional polypeptide that regulates a variety of cellular processes. Several studies have indicated that it is associated with epithelial-mesenchymal transition, angiogenesis, migration and metastases in many types of malignant tumors. We have used a wound-healing assay and a Matrigel invasion assay to evaluate the effects of TGF- $\beta 1$ and TGF- $\beta$ receptor I kinase inhibitor (TRI) on the cell motility and invasiveness of the human oral squamous cell carcinoma (OSCC) cell lines SAS-L1 and HSC-3. While TGF- 31 enhanced the migration and invasion of OSCC cells, TRI significantly suppressed the migration and invasion of these cells. Exogenous TGF- 31 up-regulated the activity of type IV collagenase (gelatinase A and gelatinase B), whereas TRI down-regulated the activity of these matrix metalloproteinases. Western blot analysis revealed that TGF- $\beta 1$ enhanced the expression of $\alpha 5, \alpha v, \beta 1, \beta 6$ and $\alpha v \beta 3$ integrin subunits, and these enhanced integrins were down-regulated by treatment with TRI. These results suggest that the inhibition of TGFB1 suppresses motility and invasiveness of OSCC cells via modulation of integrins and matrix-metalloproteinases. Therefore, targeting the TGF- $\$ 1$ signaling pathway could be beneficial in the treatment of patients with OSCC.
\end{abstract}

\section{Introduction}

Transforming growth factor (TGF)- $\beta 1$ is a multifunctional polypeptide that elicits numerous cellular effects pertinent to the metastatic process, including regulation of epithelial cell differentiation and proliferation, modulation of angiogenesis,

Correspondence to: Dr Masashi Hatori, Department of Oral and Maxillofacial Surgery, School of Dentistry, Showa University, 2-1-1 Kitasenzoku, Ota-ku, Tokyo 145-8515, Japan

E-mail: hatori@senzoku.showa-u.ac.jp

Key words: TGF-ß1, matrix metalloproteinase, integrin, squamous cell carcinoma synthesis of extracellular matrix proteins and integrin receptors, and alterations in the production of matrix-degrading proteinases and their inhibitors (1). Consistent with the idea that TGF- $\beta 1$ can act as a tumor promoter, increased expression of TGF- $\beta 1 \mathrm{mRNA}$ or protein in tumor cells and/or plasma has been correlated with advanced tumor progression in colorectal cancer, gastric carcinoma, non-small cell lung cancer (NSCLC) and prostate cancer (2-6). It is generally accepted that the components of the TGF- $\beta 1$ signal transduction pathway, i.e., the ligand, receptors, signal transducers and their transcriptional targets, are important in the suppression of tumors.

Despite advances in multimodality treatments, the 5-year survival of patients with oral squamous cell carcinoma (OSCC) remains $<50 \%$, and local recurrence and distant metastasis are major problems (7). There are scarce data on the effects of TGF- $\beta 1$ on progression and metastasis of OSCC. Thus, the purpose of this study was to evaluate the regulatory role of TGF- $\beta 1$ on cell metastasis in OSCC. The effects of TGF- $\beta$ receptor I kinase inhibitor (TRI) on motility and invasiveness of OSCC cells were also investigated.

\section{Materials and methods}

Reagents. TGF- $\$ 1$ was purchased from Wako (Tokyo, Japan). TRI was purchased from Calbiochem (San Diego, CA). As a primary antibody for Western blot analysis, integrins $\alpha 3, \alpha 5$, $\alpha v, \beta 1, \beta 3, \beta 4, \beta 6$ and $\alpha v \beta 3$ were purchased from Santa Cruz Biotechnology, Inc. (Santa Cruz, CA). Horseradish peroxidase (HRP)-conjugated mouse and rabbit anti-Ig secondary antibodies for Western blot analysis were purchased from Amersham Biosciences (Uppsala, Sweden).

Cell lines and cell culture. The SAS-L1 cells $(8,9)$ and HSC-3 cells, established from patients with squamous cell carcinoma of the tongue, were kindly donated by Professor T. Tachikawa (Department of Oral Pathology, Showa University) and purchased from RIKEN BioResource Center Cell Bank (Ibaraki, Japan), respectively. These cells were maintained as monolayers in Dulbecco's modified Eagle's medium supplemented with $10 \%$ heat-inactivated fetal bovine serum, $100 \mathrm{U} / \mathrm{ml}$ penicillin and $100 \mathrm{mg} / \mathrm{ml}$ streptomycin (complete medium). MRC-5, a fibroblast cell line, was maintained in 
modified Eagle's medium supplemented with $10 \%$ heatinactivated fetal bovine serum, $100 \mathrm{U} / \mathrm{ml}$ penicillin and $100 \mathrm{mg} / \mathrm{ml}$ streptomycin (complete medium). Subconfluent monolayers of these cells were employed in all experiments. The supernatant from the fibroblast cell line culture was employed as a chemoattractant for OSCC cells in the invasion assay.

Cell proliferation assay. OSCC cells were seeded ( $5 \times 10^{4}$ cells) in $10-\mathrm{cm}^{2}$ dishes. After $18 \mathrm{~h}$ of incubation, $1 \mathrm{ng} / \mathrm{ml}$ of TGF- $\beta 1$ and/or $1 \mathrm{mM}$ of TRI was added to the supernatant, then the cells were cultured for 12,24 , and $48 \mathrm{~h}$. The cells were then trypsinized and counted with a coulter counter (Beckman Coulter, Fullerton, CA, USA). All measurements were made in triplicate.

Cell motility assay. Cell motility was evaluated using the in vitro wound-healing assay, as previously described (10). Briefly, OSCC cells were seeded ( $1 \times 10^{5}$ cells/well) in 6-well plates. After incubation overnight, wounds were made by scratching the cell monolayer with a sterile plastic pipette tip. The culture medium was changed immediately after wounding to remove cell debris and factors released from the detached cells. Cells were treated with $1 \mathrm{ng} / \mathrm{ml}$ TGF- $\beta 1$ and/or $1 \mathrm{mM}$ TRI. Photographs were taken using phase-contrast microscopy up to $48 \mathrm{~h}$; movement of cells from the wound edges into the wound was indicative of cell motility.

Invasion assay. The membrane invasion assay was performed in Matrigel-coated invasion chambers (Becton Dickinson Labware, Franklin Lakes, NJ). Briefly, resuspended OSCC cells $\left(5 \times 10^{4}\right.$ cells $)$ were plated in the upper chamber with $1 \mathrm{ng} /$ $\mathrm{ml}$ TGF- $\beta 1$ and/or $1 \mathrm{mM}$ TRI, while control cells received vehicle only. Fibroblast (MRC-5) conditioned medium was added to the lower chamber as a chemoattractant for the OSCC cells. Following $24 \mathrm{~h}$ of incubation at $37^{\circ} \mathrm{C}$ in a humidified $5 \% \mathrm{CO}_{2}$ atmosphere, cells in the upper chamber and on the Matrigel were mechanically removed with a cotton swab. Cells adherent to the outer surface of the membrane were fixed and stained with a Diff-Quit kit (Sysmex, Hyogo, Japan) according to the assay protocol. The invading cells were counted and photographed under a microscope (Provis AXUCDM, Olympus, Tokyo, Japan) at x200 magnification. Five fields were counted per filter in each group, and the experiment was conducted in triplicate.

Measurement of type IV collagenase activity. To evaluate the effects of $1 \mathrm{ng} / \mathrm{ml}$ TGF- $\beta 1$ and/or $1 \mathrm{mM}$ TRI on gelatinase activity, cells were treated with these reagents for $24 \mathrm{~h}$ and then the total activity of gelatinase A and gelatinase B was evaluated using a type IV collagenase activity measurement kit $^{\circledR}$ (Life Kennkyuujo, Yamagata, Japan), according to the assay protocol.

Gelatin zymography. To determine gelatinase activity, cells were treated with $1 \mathrm{ng} / \mathrm{ml}$ TGF- $\beta 1$ and/or $1 \mathrm{mM}$ TRI for $24 \mathrm{~h}$ before performing SDS-PAGE gelatin zymography. Briefly, each supernatant was electrophoresed onto a $7.5 \%$ polyacrylamide gel containing $0.1 \%$ sodium dodecylsulfate (SDS) and $1 \mathrm{mg} / \mathrm{ml}$ gelatin; the same amount of total protein

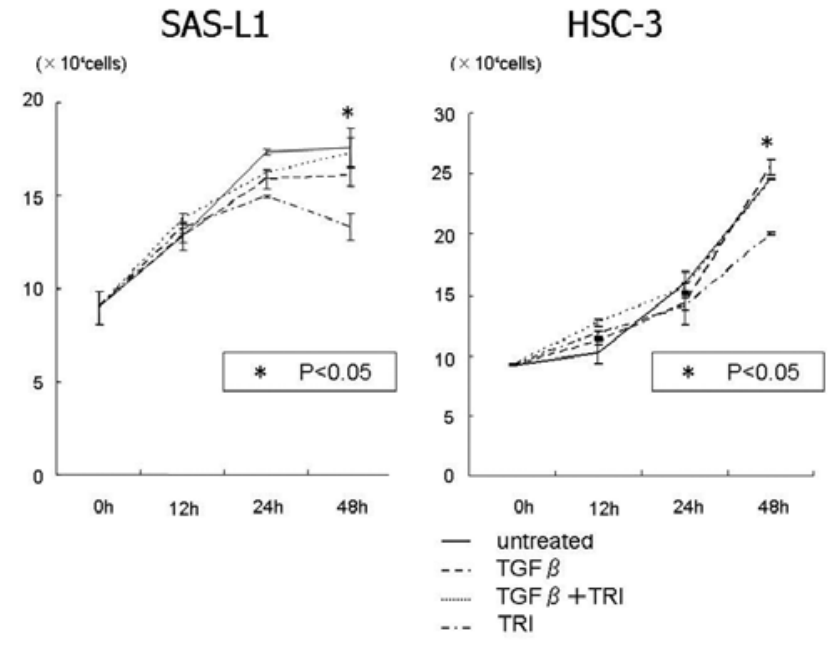

Figure 1. Effect of TGF- $ß 1$ and TRI on the proliferation of OSCC cells. SAS-L1 and HSC-3 cells were treated with TGF- 31 and/or TRI for up to $72 \mathrm{~h}$, and their proliferation was evaluated by a coulter counter.

supernatant $(10 \mu 1)$ was added to each electrophoretic lane. The gels were washed for $1 \mathrm{~h}$ in a washing buffer $(50 \mathrm{mmol} / \mathrm{l}$ Tris- $\mathrm{HCl}, \mathrm{pH} 7.4)$ containing $2 \%$ Triton $\mathrm{X}-100$ to remove the SDS. After incubating the gels in reaction buffer $(50 \mathrm{mmol} / \mathrm{l}$ Tris- $\mathrm{HCl}, \mathrm{pH} 7.4,10 \mathrm{mmol} / \mathrm{CaCl}_{2}, 1 \%$ Triton $\mathrm{X}-100,0.02 \%$ $\mathrm{NaN}_{3}$ ) at $37^{\circ} \mathrm{C}$ for $20 \mathrm{~h}$, they were stained for $30 \mathrm{~min}$ with $0.1 \%$ Coomassie Brilliant Blue R250 (Fluka Chemie AG, Neu-Ulm, Switzerland) to visualize bands of proteolytic activity. The gels were then destained in 5\% acetic acid and $10 \%$ methanol and dried directly. Sites of gelatinolytic activity were detectable as clear bands against a background of uniform staining.

Western blot analysis. Cells $\left(2 \times 10^{6}\right)$ were plated in $10 \mathrm{ml}$ of complete medium. After $18 \mathrm{~h}$ of incubation, $1 \mathrm{ng} / \mathrm{ml}$ TGF- $ß 1$ and/or $1 \mathrm{mM}$ TRI was added to the culture dishes. After a further $24 \mathrm{~h}$ of incubation, cells were lyzed in Igepal lysis buffer (20 mM HEPES, pH 7.5, $350 \mathrm{mM} \mathrm{NaCl}, 25 \%$ glycerol, $0.25 \%$ Igepal CA-630, $1 \mathrm{mM}$ sodium o-vanadate) with complete Mini ${ }^{\mathrm{TM}}$ protease inhibitor (Roche Diagnostics, Mannheim, Germany). Lysates were centrifuged (14,000 x g, $4^{\circ} \mathrm{C}, 15 \mathrm{~min}$ ), and the protein concentration was measured by Bradford assay. Protein $(20 \mu \mathrm{g})$ was separated by SDS-PAGE, transferred to Hybond ${ }^{\mathrm{TM}}$ PVDF membranes (Amersham Pharmacia Biotech, Buckinghamshire, UK), and, after blocking by incubation for $90 \mathrm{~min}$ in 5\% skim-milk buffer at room temperature, treated with the primary antibody (anti-integrin $\alpha 3$, -integrin $\alpha 5$, -integrin $\alpha v$, -integrin $\beta 1$, -integrin $\beta 3$, -integrin $\beta 4$, and -integrin $B 6$ monoclonal antibody) followed by the HRP-conjugated secondary antibody (mouse or rabbit anti-Ig antibody). Protein bands were visualized with the ECL plus $^{\mathrm{TM}}$ Western blot detection system (Amersham Pharmacia Biotech), according to the manufacturer's instructions.

\section{Results}

Cell proliferation assay. The proliferation of OSCC cells following treatment with TGF- $\beta 1$ and/or TRI was evaluated 


\section{SAS-L1}

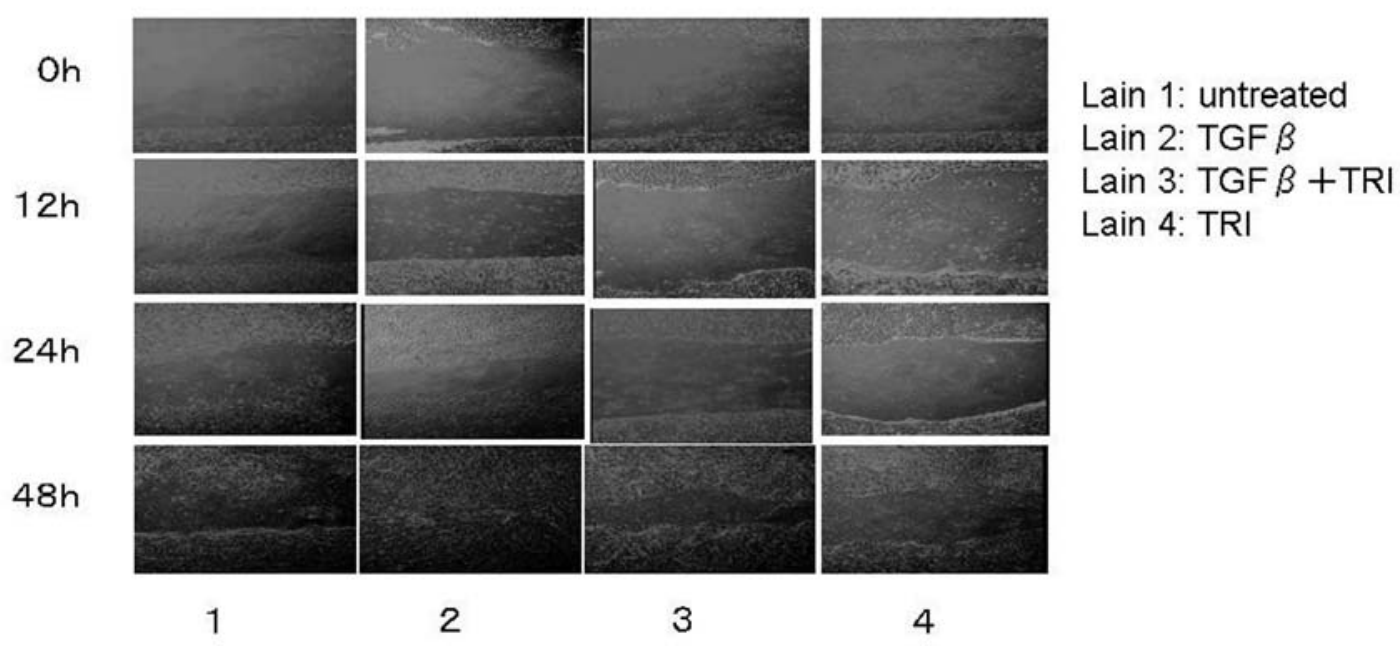

B

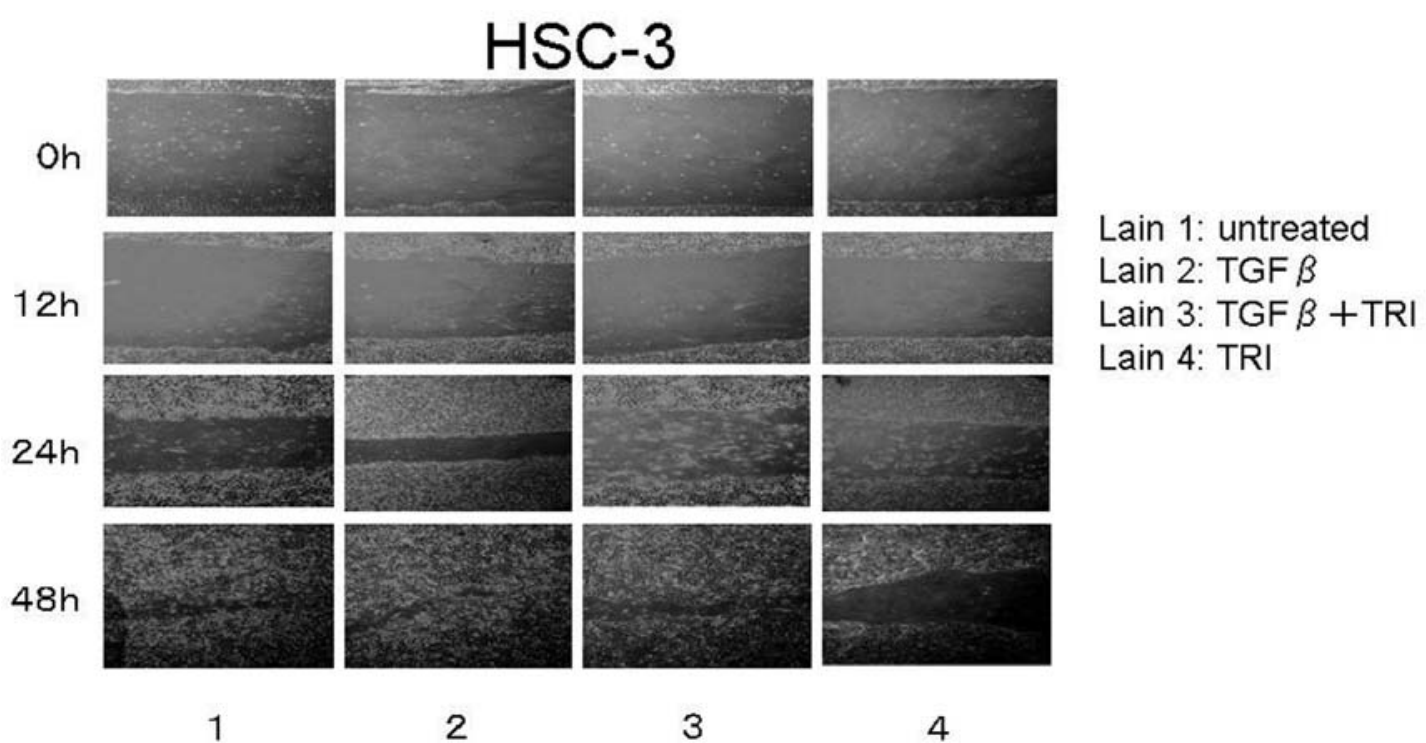

Figure 2. Effect of TGF- 31 and TRI on the motility of OSCC cells. Monolayers of SAS-L1 and HSC-3 cells were scratched using a sterile plastic pipette tip, then the cells were treated with TGF- 11 and/or TRI. Photographs were taken using phase-contrast microscopy: movement of cells from wound edges into the wounds was indicative of cell motility.

by coulter counter: neither agent showed significant effect before 24 h (Fig. 1).

Cell motility assay. The effects of TGF- $\beta 1$ and TRI on cell motility were evaluated by wound-healing assay. As shown in Fig. 2, the motility of both SAS-L1 and HSC-3 cells was increased by treatment with $1 \mathrm{ng} / \mathrm{ml}$ TGF- $\beta 1$, while TRI treatment strongly inhibited migration of these OSCC cells.

Invasion assay. To examine the effects of TGF- $\beta 1$ and TRI on the invasiveness of OSCC cells, we performed the Matrigel invasion assay. As shown in Fig. 3, the invasiveness of both cell lines was significantly increased on treatment with TGF- $\$ 1$ and significantly decreased by TRI.
Effects of TGF- $\beta 1$ and TRI on gelatinase activity. Activation of gelatinases was enhanced by treatment with TGF- $\beta 1$ and down-regulated by treatment with TRI (Fig. 4A). Gelatinolytic activities of matrix metalloproteinase (MMP)-2 and MMP-9 were also examined on the gelatin-containing gels As shown in Fig. 4B, active MMP-2 was up-regulated in the presence of TGF- $\beta 1$ and down-regulated by TRI. Neither TGF- 11 nor TRI had a significant effect on the activation of MMP-9.

Western blot analysis. Western blot analysis was used to examine the effects of TGF- $\beta 1$ and TRI on integrin expression in OSCC cells. As shown in Fig. 5, TGF- $\beta 1$ enhanced the expression of the $\alpha 5, \alpha v, \beta 1, \beta 6$ and $\alpha \mathrm{v} \beta 3$ integrin subunits, 
A

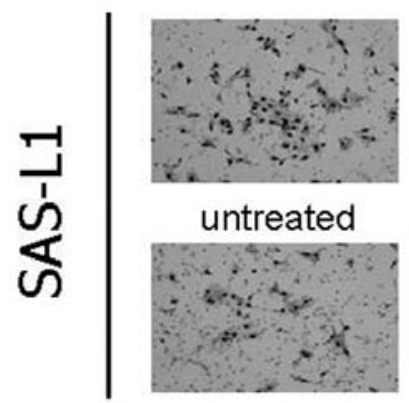

TGF $\beta+$ TRI

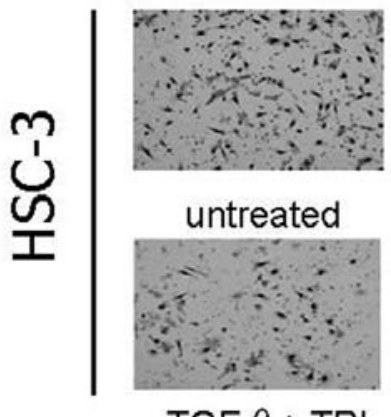

TGF $\beta+$ TRI
B

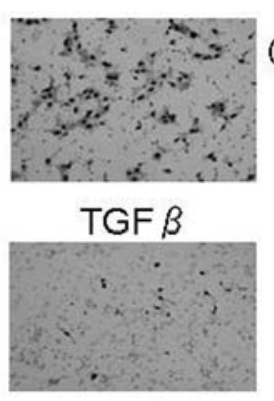

TRI

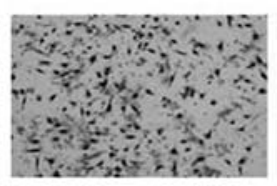

TGF $\beta$

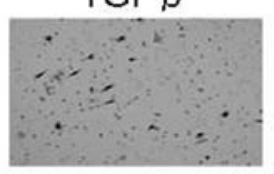

TRI
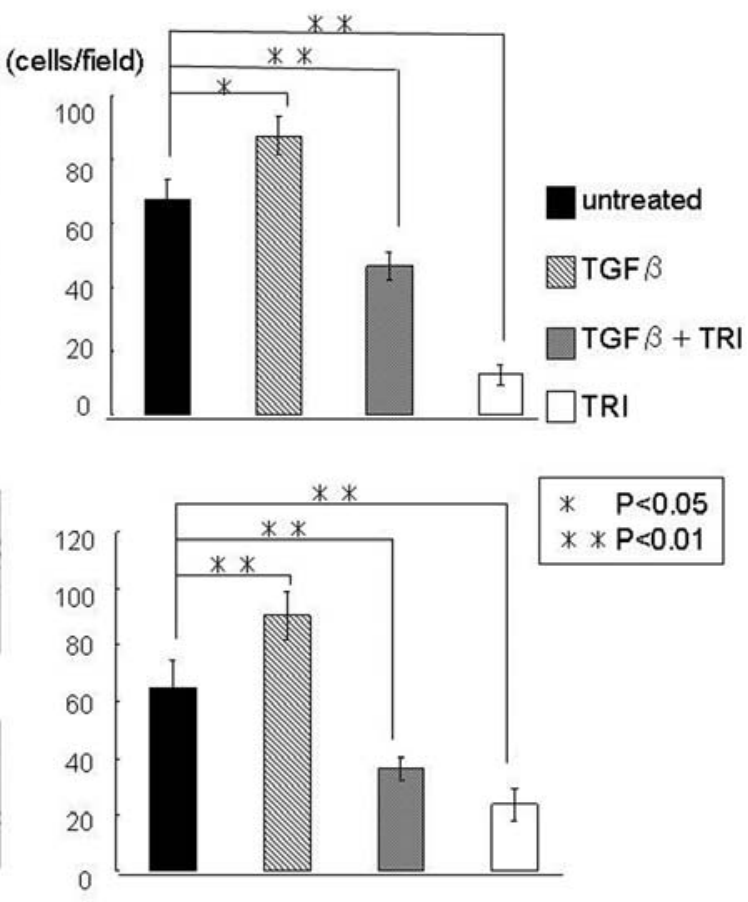

Figure 3. Effect of TGF- $\beta 1$ and TRI on the invasiveness of OSCC cells in a Matrigel invasion assay. SAS-L1 and HSC-3 cells treated with TGF- 11 and/or TRI were plated in the upper chamber. Following $24 \mathrm{~h}$ of incubation, invading cells were stained and counted under a microscope at $\mathrm{x} 200 \mathrm{magnification}$. (A) Results from a representative analysis. (B) Five fields were counted per filter in each group. Values are mean \pm standard deviation of triplicate determinations. ${ }^{*} \mathrm{p}<001,{ }^{* *} \mathrm{p}<0.05$ versus control.

A

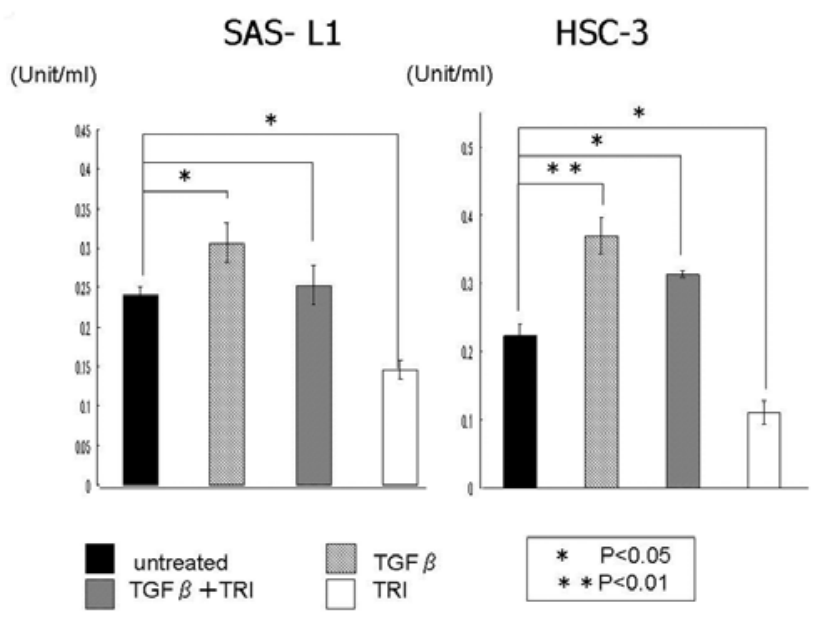

B

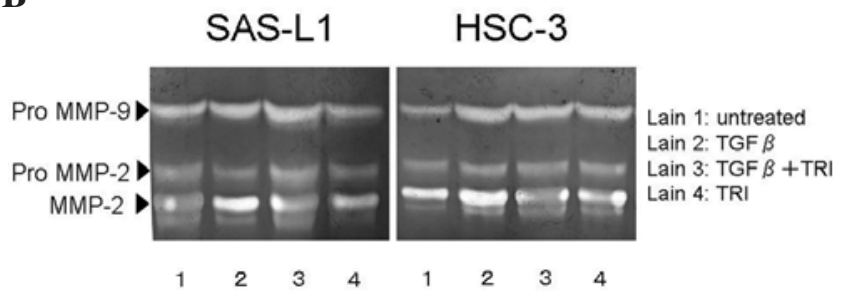

Figure 4. Effect of TGF- 11 and TRI on gelatinase activity in OSCC cells. (A) Gelatinase (type IV collagenase) activity was measured using a type IV collagenase activity measurement $\mathrm{kit}^{\circledR}$. Values are mean \pm SD of triplicate determinations. ${ }^{*} \mathrm{p}<001,{ }^{* *} \mathrm{p}<0.05$ versus control. (B) Gelatinolytic activities of MMP-2 and MMP-9 on the gelatin-containing gels. and expression of these integrins was down-regulated by treatment with TRI.

\section{Discussion}

Recent studies have suggested a significant association between high tumor expression of TGF- $\beta$ and poor prognosis in many cancers $(5,11,12)$ The 5 -year survival rate is better for patients whose gastric tumors are TGF-B1-negative than those with TGF- $\beta 1$-positive tumors (5) and an absence of TGF- $\beta$ isoforms in pancreatic tumors correlates with increased post-operative survival time (12). Intense TGF- $\beta$ staining has been shown to correlate significantly with disease progression to metastasis in breast carcinoma, prostate cancer, and colorectal cancer $(6,13,14)$ and TGF- $\beta$ serum levels are significantly higher in patients who have lymph node metastases with NSCLC or colorectal carcinoma $(2,4)$. Moreover, TGF- $\beta$ staining in colorectal and breast cancer has been shown to be stronger in the invading local lymph node metastases than the paired primary tumor site $(15,16)$. Thus, there is good evidence to suggest that TGF- $\beta$ is a potent factor that promotes metastasis in malignant tumors.

Tumor invasion and metastasis are regarded as multistep phenomena that involve proteolytic degradation of the basement membrane and extracellular matrix (ECM), and altered cell adhesion and physical movement of the tumor cells. Of these steps, degradation of the ECM is essential, and many proteinases, e.g., serine proteases and matrix metalloproteinases (MMPs), are involved $(17,18)$. MMPs are a family of highly homologous extracellular zinc- and 


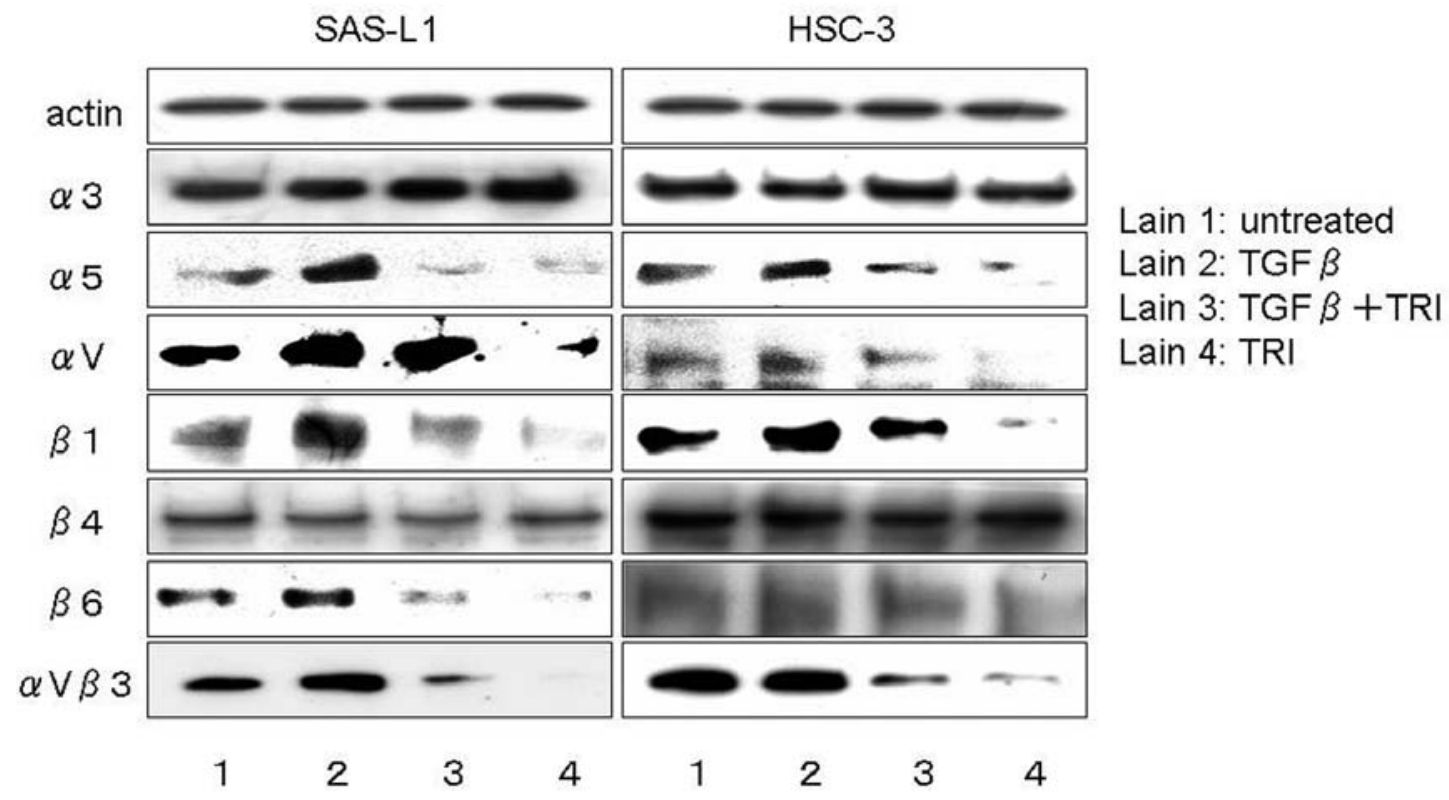

Figure 5. Western blot analysis of integrin subunits in OSCC cells. SAS-L1 and HSC-3 cells were cultured with TGF-ß1 and/or TRI for 24 h. Cells were lyzed and Western blot analysis was performed.

calcium-dependent endopeptidases with enzymatic activity against almost all protein components of the ECM. Based on domain structure and substrate specificity, MMPs can be divided into four subclasses: collagenases, gelatinases, stromelysins, and membrane-type MMPs (19). We evaluated type IV collagenase (gelatinase A and gelatinase B) activity because the main component of the basement membrane is type IV collagen: several studies have indicated a correlation between increased gelatinase activity and metastatic potential in cancer cells (20-22). MMP-2 and -9 in particular are consistently detected in malignant tissues and associated with tumor growth and progression $(23,24)$.

Our results indicated that TGF- $\beta 1$ enhanced invasiveness of OSCC cells via activation of gelatinases, MMP-2 in particular, and that TRI inhibited activation of MMP-2.

To examine the effects of TGF- 31 on the cell motility of OSCC cells, we performed a wound-healing assay. As shown in Fig. 2, TGF-ß1 up-regulated the cell motility of OSCC cells, while TRI strongly inhibited cellular migration. Integrins are a family of cell surface adhesion molecules that mediate cell adhesion and initiate signaling pathways that regulate cell spreading, migration, differentiation, and proliferation. Integrins link the ECM to intracellular cytoskeletal structures and signaling molecules and are implicated in the regulation of a number of cellular processes, including adhesion, signaling, motility, survival, gene expression, growth and differentiation (25). Integrins comprise two transmembrane subunits; $\alpha$ and $\beta$. In mammals, $18 \alpha$ and $8 ß$ subunits associate in various combinations to form 24 integrins that can bind to various ECM ligands $(26,27)$ and it is well known that these integrins play pivotal roles in cell migration and adhesion in cancer cells. Therefore, we explored the effect of TGF- $\beta 1$ on the expression of integrin subunits in these OSCC cells. Our results revealed that TGF- $\beta 1$ enhanced the expression of integrins $\alpha 5, \alpha \mathrm{v}, \beta 6, \alpha \mathrm{v}$, and $\beta 3$, whereas TRI suppressed these integrin subunits. The results shown here suggest that TGF- $\beta 1$ is a major enhancer for motility and invasiveness of OSCC cells via modulation of integrins and matrix-metalloproteinases. In addition, TRI, the kinase inhibitor of TGF- $\$ 1$, strongly inhibited the motility and invasiveness of the OSCC cells via down-regulation of the expression of integrins and matrixmetalloproteinases. Therefore, targeting the TGF- 31 signaling pathway could be beneficial in the treatment of OSCC.

\section{References}

1. Wright JA, Turley EA and Greenberg H: Transforming growth factor beta and fibroblast growth factor as promoters of tumor progression to malignancy. Oncogenesis 4: 473-492, 1993.

2 Hasegawa Y, Takanashi S, Kanehira Y, Tsushima T, Imai T and Okumura K: Transforming growth factor- $\beta 1$ level correlates with angiogenesis, tumor progression, and prognosis in patients with nonsmall cell lung carcinoma. Cancer 91: 964-971, 2001.

3. Tsushima H, Kawata S, Tamura S, et al: High levels of transforming growth factor $\beta 1$ in patients with colorectal cancer: association with disease progression. Gastroenterology 110 : 375-382, 1996.

4. Shim KS, Kim KH, Han WS and Park EB: Elevated serum levels of transforming growth factor- $\beta 1$ in patients with colorectal carcinoma: its association with tumor progression and its significant decrease after curative surgical resection. Cancer 85: 554-561, 1999

5. Saito H, Tsujitani $\mathrm{S}$ and Oka S, et al: The expression of transforming growth factor- $\beta 1$ is significantly correlated with the expression of vascular endothelial growth factor and poor prognosis of patients with advanced gastric carcinoma. Cancer 86: 1455-1462, 1999.

6. Wikstrom P, Stattin P, Franck-Lissbrant I, et al: Transforming growth factor $\beta 1$ is associated with angiogenesis, metastasis, and poor clinical outcome in prostate cancer. Prostate 37: 19-29, 1998.

7. Young MR: Protective mechanisms of head and neck squamous cell carcinomas from immune assault. Head Neck 28: 462-470, 2006.

8. Aida T, Arai J, Irie T, Yoshizawa M, et al: Establishment and characterization of human oral squamous cell carcinoma cell line with highly lymph node metastatic potential. J Jpn Soc Oral Tumor 13: 66-72, 2001. 
9. Takahashi K, Kanazawa H, Akiyama Y, et al: Establishment and characterization of a cell line (SAS) from poorly differentiated human squamous cell carcinoma of the tongue. Kokubyo Gakkai Zasshi 38: 20-28, 1989.

10. Shaw RJ, Paez JG, Curto M, et al: The nf2 tumor suppressor, merlin, functions in Rac-dependent signaling. Dev Cell 1: 63-72, 2001.

12. Friess H, Yamanaka Y, Buchler M, et al: Enhanced expression of transforming growth factor $B$ isoforms in pancreatic cancer correlates with decreased survival. Gastroenterology 105: 1846-1856, 1993.

13. Walker RA and Dearing SJ: Transforming growth factor $B 1$ in ductal carcinoma in situ and invasive carcinomas of the breast. Eur J Cancer 28: 641-644, 1992.

14. Friedman E, Gold LI, Klimstra D, et al: High levels of transforming growth factor $B 1$ correlate with disease progression in human colon cancer. Cancer Epidemiol Biomarkers Prev 4: 549-554, 1995.

15. Dalal BI, Keown PA and Greenberg AH: Immunocytochemical localization of secreted transforming growth factor- $\beta 1$ to the advancing edges of primary tumors and to lymph node metastases of human mammary carcinoma. Am J Pathol 143: 381-389, 1993.

16. Picon A, Gold LI, Wang J, et al: A subset of metastatic human colon cancers expresses elevated levels of transforming growth factor B 1. Cancer Epidemiol Biomarkers Prev 7: 497-504, 1998.

17. Liotta LA and Stetler-Stevenson WG: Tumor invasion and metastasis: an imbalance of positive and negative regulation. Cancer Res 51: 5054-5059, 1991.

18. Lukashev ME and Werb Z: ECM signaling: orchestrating cell behaviour and misbehaviour. Trends Cell Biol 8: 437-441, 1998.
19. Chambers AF and Matrisian LM: Changing views of the role of matrix metalloproteinases in metastasis. J Natl Cancer Inst 89: 1260-1270, 1997.

20. Yang C, Zeisberg M, Lively JC, et al: Integrin alpha1beta1 and alpha2beta1 are the key regulators of hepatocarcinoma cell invasion across the fibrotic matrix microenvironment. Cancer Res 63: 8312-8317, 2003.

21. Robinson CM, Stone AM, Shields JD, et al: Functional significance of MMP-2 and MMP-9 expression by human malignant oral keratinocyte cell lines. Arch Oral Biol 48: 779-786, 2003.

22. Bernardo MM and Fridman R: TIMP-2 (tissue inhibitor of metalloproteinase-2) regulates MMP-2 (matrix metalloproteinase-2) activity in the extracellular environment after pro-MMP-2 activation by MT1 (membrane type 1)-MMP. Biochem J 374: 739-745, 2003.

23. Duffy MJ: The role of proteolytic enzymes in cancer invasion and metastasis. Clin Exp Metast 10: 145-155, 1992.

24. Liotta LA, Tryggvason K, Garbisa S, Hart I, Foltz CM and Shafie S: Metastatic potential correlates with enzymatic degradation of basement membrane collagen. Nature 284: 67-68, 1980.

25. Miranti CK and Brugge JS: Sensing the environment: a historical perspective on integrin signal transduction. Nat Cell Biol 4: E83-E90, 2002.

26. Giancotti FG and Ruoslahti E: Integrin signaling. Science 285: 1028-1032, 1999.

27. Hynes RO: Integrins: bidirectional, allosteric signaling machines. Cell 110: 673-687, 2002. 